\title{
A Reuse Evaluation for Solar-Cell Silicon Wafers via Shift Revolution and Tool Rotation Using Magnetic Assistance in Ultrasonic Electrochemical Micromachining
}

\author{
P.S.Pa \\ Department of Digital Content Design, Graduate School of Toy and Game Design, National Taipei University of Education, \\ No. 134, Sector 2, Heping E. Road, Taipei City 106, Taiwan
}

Correspondence should be addressed to P. S. Pa; myhow@tea.ntue.edu.tw

Received 19 September 2013; Revised 23 November 2013; Accepted 27 November 2013

Academic Editor: Liang-Sheng Liao

Copyright $\odot 2013$ P. S. Pa. This is an open access article distributed under the Creative Commons Attribution License, which permits unrestricted use, distribution, and reproduction in any medium, provided the original work is properly cited.

\begin{abstract}
A new reuse fabrication using a tool module with rotation and revolution through a process of magnetic assistance in ultrasonic electrochemical micromachining (UEMM) for removal of the surface layers from silicon wafers of solar cells is demonstrated. The target of the proposed reuse fabrication method is to replace the current approach, which uses strong acid and grinding and may damage the physical structure of silicon wafers and pollute to the environment. A precisely engineered clean production approach to removal of surface microstructure layers from silicon wafers is to develop a mass production system for recycling defective or discarded silicon wafers of solar cells that can reduce pollution and cost. The high revolution speed of the shift with the high rotation speed of the designed tool increases the discharge mobility and improves the removal effect associated with the high feed rate of the workpiece. High frequency and high power of ultrasonic with large electrolyte flow rate and high magnetic strengths with a small distance between the two magnets provide a large discharge effect and good removal; only a short period of time is required to remove the epoxy film and $\mathrm{Si}_{3} \mathrm{~N}_{4}$ layer easily and cleanly.
\end{abstract}

\section{Introduction}

The success of solar-cell technology that allows the conversion of solar energy directly into electric powers represents an important milestone for the energy industry worldwide $[1,2]$. In view of energy shortages, the need for environmental protection, and a predicted future lack of silicon material, the research and application of solar optoelectronics have become globally significant. In addition to its great potential for development, solar energy also has the advantages of abundance, accessibility, and that of causing less pollution than the alternatives. The solar optoelectronic industry is becoming increasingly important and it is expected that solar energy will replace petroleum as the most important source of energy in the foreseeable future [3]. Production of photovoltaic modules on a commercial scale dates back to 1980s. Photovoltaics (PV) module manufacturers provide a work warranty of 20-30 years, so modules produced back in the 1980s should be put out of commission and recycled during this decade, while modules manufactured in 2000 should be recycled by 2030. In recent years, photovoltaic power generation systems have been gaining unprecedented attention as an environmentally beneficial method to solve the energy problem. From the economic point of view, the pure silicon, which can be recapture from the used cells, is the most important material due to its cost and shortage. Ewa et al. selected methods of used or damaged module and cells recycling and experimental results are presented. Advantages and disadvantages of the techniques are described, what could be helpful during the optimization of the method. The recycling process of PV module consists of two main steps: separation of cells and its refining. During the first step, cells are separated due to the thermal or chemical methods usage. Separation of cells from damaged PV modules through chemical treatment is not economically worthwhile; a far more better solution is to use thermal treatment. Next, the 
separated cells are refining. During this process, useless layers are removed. The implementation of laser techniques in unwanted layer removal stage, in comparison with chemical treatment, is also disadvantageous. An optimal solution is to use thermal treatment for cell separation and chemical treatment for removing the metallization, contacts, antireflective coating, and the n-p junction [4-6].

Electromagnetic metal forming (EMF) is an example of a high-speed formation process that is determined by the dynamics of a coupled electromagnetic-mechanical system. "Magnetic" pressure provides the necessary kinetic energy. A magnetic pulse accelerates the workpiece up to a certain velocity (such as $200-300 \mathrm{~m} / \mathrm{s}$ ) and the material is driven into the die, causing forming by impact $[7,8]$. Other applications include embossing, blanking, and drawing. Magnetic deburring has also been used for holes drilled into tubes. The results showed that burrs inside pipes could be removed using a magnetic process and the height of the burr could be successfully decreased from $163 \mu \mathrm{m}$ to $1 \mu \mathrm{m}$. This magnetic deburring can be effectively used inside long tubes [9]. The formulation of a thermomagneto mechanism is used to simulate electromagnetic sheet metal forming processes (EMF). In this process, deformation of the workpiece is achieved by the interaction of a current generated in the workpiece by a magnetic field from a coil adjacent to the workpiece. For authentic industrial applications, however, the modeling of three-dimensional formation operations becomes crucial for an effective process design. The implementation of such a 3D model still represents work in progress. Results shown in the study are restricted to the axisymmetric case [10]. Ultrasonics has played an important role in industry since 1927 [11]. Conventional ultrasonic machining (USM) uses an abrasive slurry and a vibrating tool (typically $10-15 \mu \mathrm{m}$ in amplitude and $15-30 \mathrm{kHZ}$ in frequency). The abrasives are mobilized by the vibrating tool to cut the material. Ultrasonics have also been widely applied in welding, metallurgy, cleaning, measurement, and communications [12]. Ceramic and composite materials can be machined using ultrasonics [13]. Gilmore compares various nontraditional machining methods for machining ceramics, including grinding, ultrasonics, electrical discharge machining, laser beam machining, and water jet machining. Gilmore found that ultrasonic machining has distinct advantages over other machining methods [14]. Electrochemical machining (ECM) involves the use of corrosive chemical solutions to etch the surface of a workpiece. This approach is beneficial for avoiding deformation and deckled edges and is also applicable to brittle materials. The device and operational costs are low and design changes are less expensive. Related applications can be seen in industry such as chemical blanking, milling, and engraving [15].

Electrochemical machining (ECM) involves the connection of a workpiece between the anode of a DC power supply and a cathode. An electrolyte between the anode workpiece and the cathode causes part of the workpiece to be dissolved in an electrochemical (ECM) reaction [16]. The main difficulty in the implementation of ECM lies in the design of the electrode owing to the complex process of metal removal [17]. Previous studies show that the size of the gap between the electrode and the workpiece directly affects the current conditions and the electrolyte dregs discharge [18]. The ECM process is still underutilized owing to a lack of understanding of the mechanism of metal removal and difficulties involved in tool design. Even for simple cases, it is not possible to accurately predict work profiles [19]. A wide range of different types of electrode have also been developed for electropolishing [20-24].

Silicon wafers are the key material for transistors in integrated circuits and are the main component in microprocessors, computer memory, and almost every electronic device in use today. At present the greatest challenge facing the solar-energy industry is material shortage. In view of this, it is necessary to develop a novel and more effective recycling technology for silicon wafer manufacturers to improve their competitiveness. Currently a proportion of used wafers are recycled and refurbished to reduce manufacturing costs and waste because recycled wafers cost less than half that of new ones. However, the most common recycling process involves abrasion, etching, polishing, and cleaning in which part of the surface layer of the wafer is removed. An alternative approach, that is faster and cheaper than the usual Chemical \& Mechanical Planarization (CMP), is to etch the wafers with a hydrofluoric acid (HF) solution $[25,26]$. This study introduces a newly designed tool that rotates on two axes in a process that combines ultrasonic electrochemical micromachining (UEMM) with magnetic assistance for the removal of the hybrid composites coatings from the surface of solar-cell silicon wafers. A clean manufacturing approach for the removal of defective surface films is offered. This is a low polluting recycling process that is suitable for the mass production of solar-cell silicon wafers from recovered or defective items. The object of this study is the demonstration of this recycling system as a replacement of the usual methods that use strong acids and abrasion that can damage the silicon wafers and are certainly harmful to the environment. The proposed system allows defective solar-cell wafers from the production line, as well as used ones, to be recycled and returned to production. This process will lower costs, raise efficiency, and reduce pollution without loss of silicon (because no abrasion is involved) and the recycled wafers can be returned to the production line.

\section{Specifications for Solar Cell Silicon Wafer Recycling [25, 27]}

\subsection{Engineering Specifications}

(a) To successfully remove the defective surface layer from solar cell silicon wafers, the recycled silicon wafers shall retain no metal elements or residue on the surface and should be acceptable for return to production.

(b) For in-house recycling lines, optional etching of defective films on solar cell silicon wafers enables recycled silicon wafers with no metal elements or residue on the surface to be obtained. They are then acceptable for return to production. 


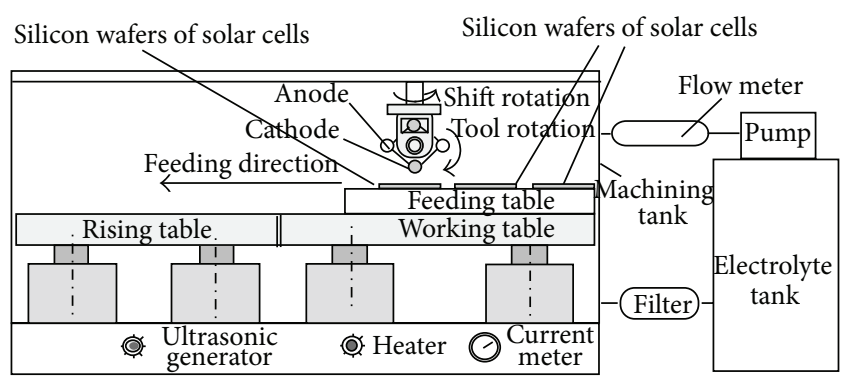

FIGURE 1: Experimental setup of recycling system for solar-cell silicon wafers.

\subsection{Commercial Specifications}

(a) Green manufacturing based on the recycling of defective items to reduce the waste of solar-cell silicon wafers is to be introduced and used by the leading wafer manufacturers in Taiwan and other countries.

(b) The goal of the project is to establish a mechanical module for the recycling of solar-cell silicon wafers that is applicable to the equipment, processing and manufacturing technologies to facilitate the introduction of these services to Taiwanese and foreign manufacturers and to build recycling lines that meet the needs of the manufacturers.

\subsection{Technical Specifications}

(a) The defective film on solar cell silicon wafers is partially or entirely removed to reduce manufacturing costs.

(b) The customized recycling lines shall meet the manufacturers' needs for the recycling of defective wafers. In addition, the recycling lines shall help reduce cost and conserve material while providing complete recycling and reducing pollution.

\section{Design Process}

This study applies to microstructure removal $(\mu \mathrm{m})$. The experimental setup is shown in Figure 1 and was derived by design analyses. This was taken as a basis for the development of a process combining microelectroetching and ECM of solar-cell silicon wafers to remove the defective thin film from the surface of the wafers. Conventional $6^{\prime \prime}$ solar-cell silicon wafers were used in these experiments.

\section{Experimental Setup and Parameters}

The workpieces used were solar-cell silicon wafers $6^{\prime \prime}$ in diameter and $0.2 \mathrm{~mm}$ thick and were immersed in electrolyte in the tank for the recycling process. The equipment used for the precision removal of the composite epoxy and $\mathrm{Si}_{3} \mathrm{~N}_{4}$ layers using magnetic assistance in ultrasonic electrochemical micromachining (UEMM) included two magnets,

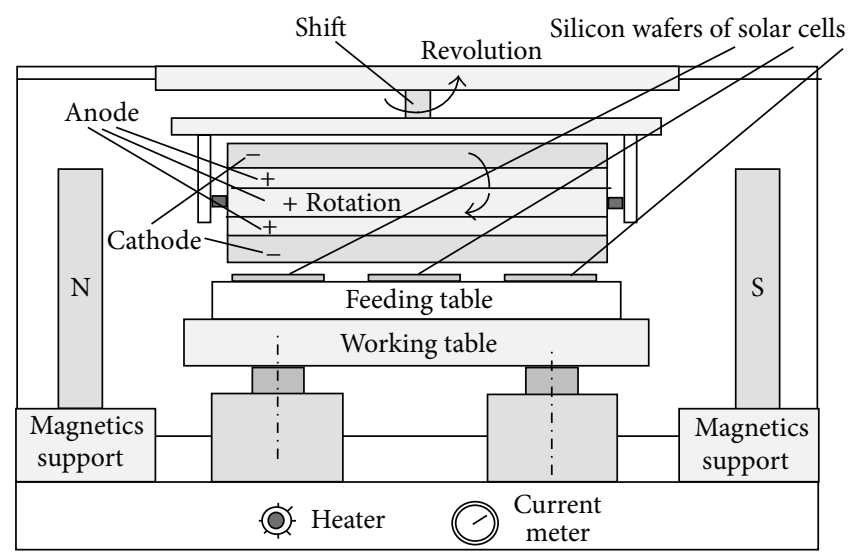

FIGURE 2: Configuration of the magnetic assistance mechanism.

an ultrasonic generator, a DC power supply, a heater, a pump, a flow meter, an electrolyte tank, and a filter. The experimental setup of the recycling system is schematically illustrated in Figure 1. The configuration of the magneticassistance mechanism is shown in Figure 2. The configuration of tool module with rotation and revolution (shift) is shown in Figure 3(a). The configuration of the newly designed tool and workpiece (solar-cell silicon wafers) is shown in Figure 3(b). During the current experiment, the tool was supplied with continuous DC. The process removed $8 \mu \mathrm{m}$ of epoxy film and $0.2 \mu \mathrm{m}$ of $\mathrm{Si}_{3} \mathrm{~N}_{4}$ from the surface of the silicon wafers. The electrolyte used was $15 \%$ wt $\mathrm{NaNO}_{3}$ and $5 \%$ wt PO4-3-P phosphoric acid. The temperature of the electrolyte was $60^{\circ} \mathrm{C}$. The continuous DC current $(I)$ was $150 \mathrm{~A}$ and the voltages $(E)$ used were $40,60,80$, or $100 \mathrm{~V}$. The feed rate of the workpiece (solar-cell silicon wafers) ranged from 50 to $500 \mathrm{~mm} / \mathrm{min}$. The noncontact distance $(y)$ from the anode to the epoxy film surface was $6,7,8,9$, or $10 \mathrm{~mm}$. The combination of frequency, ultrasonic power, and flow rate of the electrolyte used was $(50 \mathrm{kHZ} / 50 \mathrm{~W}, 10 \mathrm{~L} / \mathrm{min}),(50 \mathrm{kHZ} / 100 \mathrm{~W}$, $20 \mathrm{~L} / \mathrm{min}),(100 \mathrm{kHZ} / 100 \mathrm{~W}, 30 \mathrm{~L} / \mathrm{min})$, and $(100 \mathrm{kHZ} / 150 \mathrm{~W}$, $40 \mathrm{~L} / \mathrm{min}$ ). The combination of magnetic strength (magnetic field intensity) and the distances between the two magnets was (1000 Gauss, $1000 \mathrm{~mm}),(2000$ Gauss, $1200 \mathrm{~mm})$, (3000 Gauss, $1400 \mathrm{~mm}$ ), and (4000 Gauss, $1600 \mathrm{~mm}$ ). The combination of tool revolution (shift) and tool rotational speeds used was $(200 \mathrm{rpm}, 300 \mathrm{rpm}),(400 \mathrm{rpm}, 500 \mathrm{rpm})$, $(600 \mathrm{rpm}, 700 \mathrm{rpm})$, and $(800 \mathrm{rpm}, 900 \mathrm{rpm})$. The combination of the anode radius $\left(r_{a}\right)$ and the cathode radius $\left(r_{c}\right)$ was $(10 \mathrm{~mm}, 10 \mathrm{~mm}),(15 \mathrm{~mm}, 15 \mathrm{~mm}),(20 \mathrm{~mm}, 20 \mathrm{~mm})$, and $(25 \mathrm{~mm}, 25 \mathrm{~mm})$. The diameter $\left(D_{c}\right)$ of the cathode was $74 \mathrm{~mm}$ (with a $4 \mathrm{~mm}$ gap between anode and cathode), $72 \mathrm{~mm}$ (with a $5 \mathrm{~mm}$ gap between anode and cathode), $70 \mathrm{~mm}$ (with a $6 \mathrm{~mm}$ gap between anode and cathode), or $68 \mathrm{~mm}$ (with a $7 \mathrm{~mm}$ gap between anode and cathode). All workpieces were cleaned in water after the recycling process and dried in air. The thickness of epoxy and $\mathrm{Si}_{3} \mathrm{~N}_{4}$ nanostructures removed was determined by measurements made at more than two locations on the wafer using a NanoSpec Film Thickness Measurement System (Nanospec Film Analyzer 3000). 


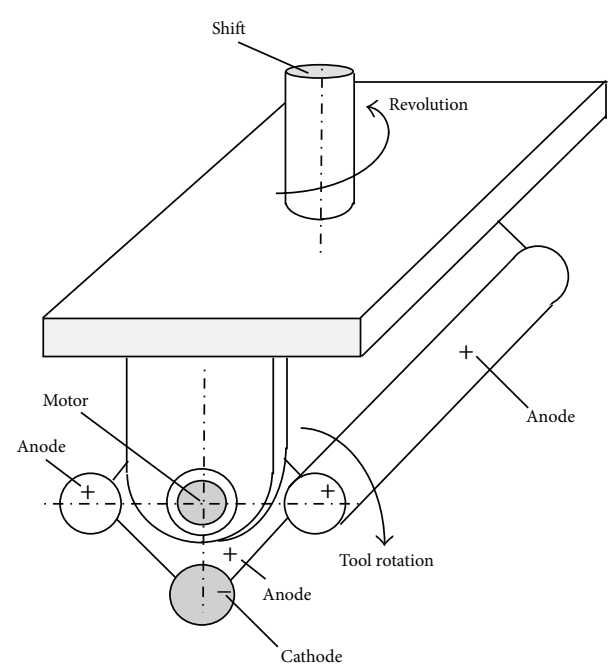

(a) Configuration of tool module with rotation and revolution

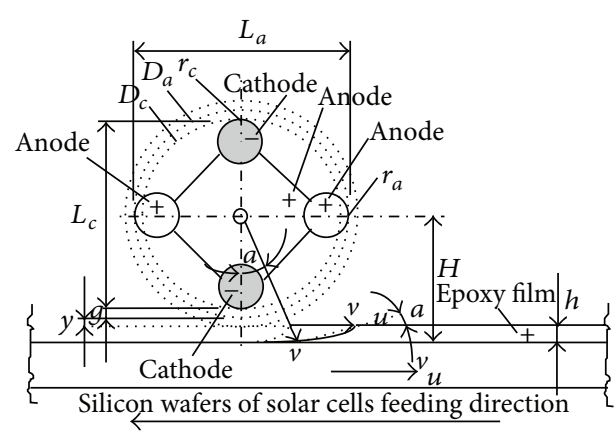

$y$ : nonecontact distance

(from the anode to the epoxy film surface)

$g$ : gap between the anode and the cathode

$h$ : removal depth

$L_{a}$ : length of the anode

$L_{c}$ : length of the cathode

$D_{a}$ : rotational diameter of the anode

$D_{c}$ : rotational diameter of the cathode

$r_{c}$ : port radius of the cathode

$r_{a}$ : port radius of the anode

(b) Configuration of designed tool and workpiece (silicon wafers of solar cells)

Figure 3: Geometry of the designed tool.

\section{Results and Discussion}

Figure 4 shows a high removal rate for the composite layers of silicon nitride $\left(\mathrm{Si}_{3} \mathrm{~N}_{4}\right)$ and epoxy using different combinations of frequency, ultrasonic power, and flow rate of the electrolyte. It can clearly be seen that the effect of ultrasonics on the electrochemical micromachining process (UEMM) is to improve the removal rate. The higher the frequency/power or electrolyte flow rate, the better the removal effect. The reason could be that the ultrasonic vibration energy and a high electrolyte flow rate facilitates the discharge of dregs from the tight machining gap.

Figure 5 shows the results of a test of different combinations of magnetic strength (magnetic field intensity) and the distance between the two magnets. The results show that the combination of high magnetic strength and short distance between the two magnets corresponds to a higher removal rate of the composite layers of epoxy and silicon nitride $\left(\mathrm{Si}_{3} \mathrm{~N}_{4}\right)$. It is also likely that the high intensity magnetic field facilitates dregs discharge. A combination of high magnetic field strength and small distance also allows a higher workpiece feed rate with a resultant reduction of machining time and cost.

As shown in Figure 6 an appropriate workpiece (solar-cell silicon wafer) feed rate and a sufficient current flow ensure that the composite layers of epoxy and $\mathrm{Si}_{3} \mathrm{~N}_{4}$ are completely removed. A high feed rate reduces the power transmission efficiency per unit area of wafer surface, while a lower rate increases it. In a case where the feed rate is high, it may be that there is insufficient electrolytic power for complete removal of the layers. But if the feed rate is too low this will increase processing time and also result in higher costs. The experimental results show that, for effective and complete removal of the epoxy and silicon nitride layers from the wafers, several combinations of settings for feed rate and continuous DC voltage have been found to give optimum results: $40 \mathrm{~V}$ with $300 \mathrm{~mm} / \mathrm{min}, 60 \mathrm{~V}$ with $325 \mathrm{~mm} / \mathrm{min}, 80 \mathrm{~V}$ with $350 \mathrm{~mm} / \mathrm{min}$, and $100 \mathrm{~V}$ with $375 \mathrm{~mm} / \mathrm{min}$.

According to the formula for the theoretical removal rate of a pure metal derived from Faraday's Law $[16,26]$,

$$
W=\frac{I T M}{F n},
$$

where $I$ is the current, $T$ is the time, and $F$ is the Faraday constant.

From Figure 4, for an alloy, let $R=W / A T$ and $\omega=R / \rho$; then

$$
\begin{gathered}
\Delta X=\frac{E \sigma \Delta t}{\rho F(n / M) X}, \\
\frac{E \sigma}{\rho F n}=C, \\
\Delta X=\frac{C \Delta t}{X}, \\
X d X=C d t,
\end{gathered}
$$




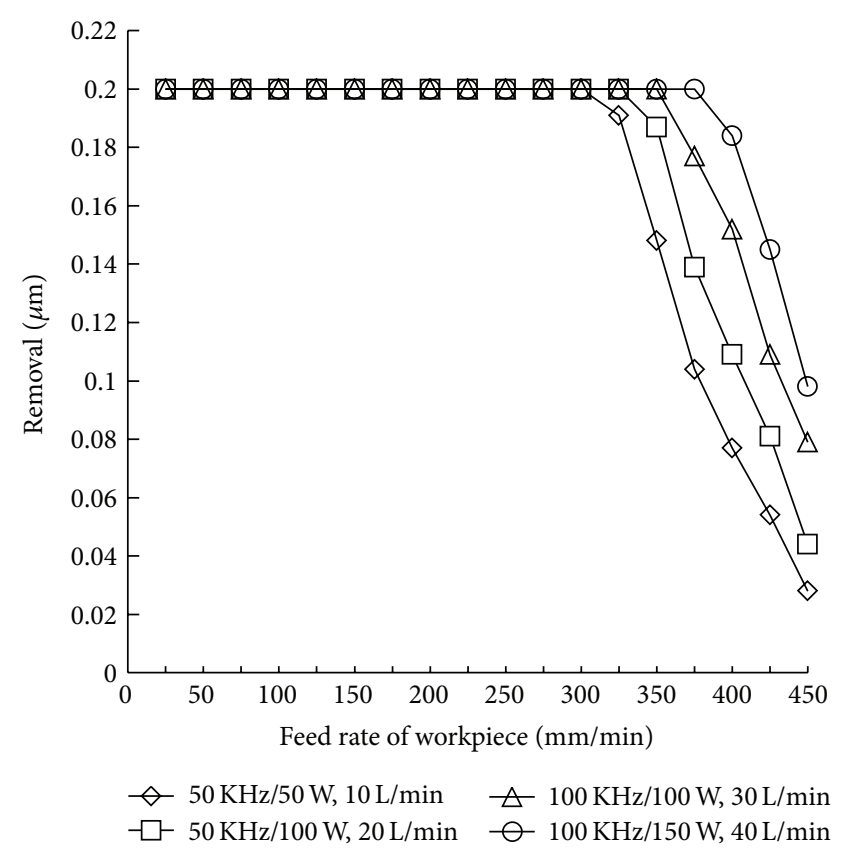

(a) Amount of $\mathrm{Si}_{3} \mathrm{~N}_{4}$ layer removed

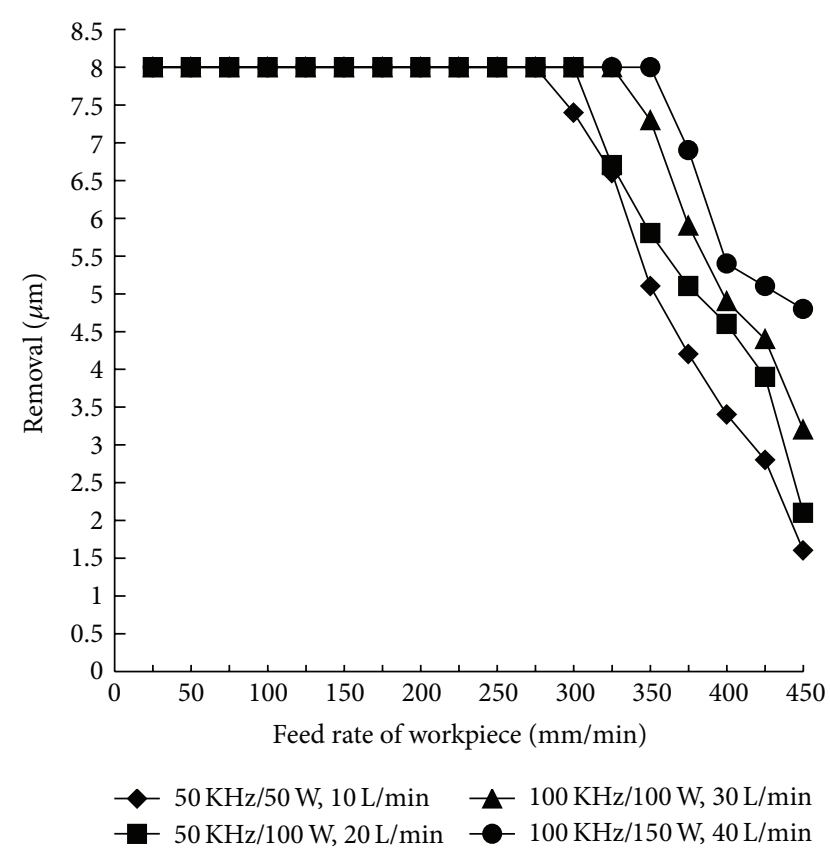

(b) Amount of epoxy film removed

Figure 4: Amount of $\mathrm{Si}_{3} \mathrm{~N}_{4}$ layer and epoxy film removed using different combinations of frequency, ultrasonic power, and electrolyte flow rate (phosphoric acid, $\mathrm{NaNO}_{3} 15 \% \mathrm{wt}, \mathrm{PO} 4-3-\mathrm{P} 5 \% \mathrm{wt}, 60^{\circ} \mathrm{C}$, continuous DC, $150 \mathrm{~A}, 80 \mathrm{~V}, 4000$ Gauss, shift $800 \mathrm{rpm}$, and tool $900 \mathrm{rpm}$ ).

$$
\begin{gathered}
\int_{g+y}^{g+y+h} X d X=\int_{0}^{t} C d t, \\
{[g+y+h]^{2}-(g+y)^{2}=\frac{2 E T \sigma}{\rho F(n / M)},} \\
{[g+y+h]=\left[\frac{2 E T \sigma}{\rho F(n / M)}+(g+y)^{2}\right]^{1 / 2},} \\
h=\left[\frac{2 E T \sigma}{\rho F(n / M)}+(g+y)^{2}\right]^{1 / 2}-(g+y) .
\end{gathered}
$$

From Figure 4, for an alloy,

$$
\begin{aligned}
h= & {\left[\frac{2 E T \sigma}{\rho F\left(\left(n_{A} / M_{A}\right) a_{A}+\left(n_{B} / M_{B}\right) a_{B}+\cdots\right)}+(g+y)^{2}\right]^{1 / 2} } \\
& -(g+y), \\
h= & {\left[\frac{2 T(I / A)(g+y)}{\rho F\left(\left(n_{A} / M_{A}\right) a_{A}+\left(n_{B} / M_{B}\right) a_{B}+\cdots\right)}+(g+y)^{2}\right]^{1 / 2} } \\
& -(g+y),
\end{aligned}
$$

$$
\begin{aligned}
=\left\{( g + y ) \left[\frac{2 T I_{A}}{\rho \mathrm{F}\left(\left(n_{A} / M_{A}\right) a_{A}+\left(n_{B} / M_{B}\right) a_{B}+\cdots\right)}\right.\right. \\
+(g+y)]\}^{1 / 2}-(g+y),
\end{aligned}
$$

where $n_{i}$ is the atomic number, $a_{i}$ is the proportion of composition, $M_{i}$ is the atomic mass, $A$ is the electrochemical etching area, $\rho$ is the density of the workpiece, $E$ is the voltage across the gap, $\sigma$ is the reciprocal resistance of the electrolyte, and $\omega$ is the etching rate in the longitudinal direction. From the above equations, the theoretical feed rate of the workpiece for a given material can be calculated.

From Figure 4,

$$
H=\frac{L_{c}}{2}+(g+y)+h,
$$

where $g$ is the width of the gap between the circular-rhombus tool and the surface of the solar-cell silicon wafer, $D_{c}$ is the length of the major axis of the cathode, and $h$ is the microelectroetching removal depth:

$$
\begin{gathered}
\cos \alpha=\frac{H-h}{H}=\frac{\left(L_{c} / 2\right)+(g+y)}{\left(L_{c} / 2\right)+(g+y)+h}, \\
\omega \csc \alpha=\omega_{v} .
\end{gathered}
$$




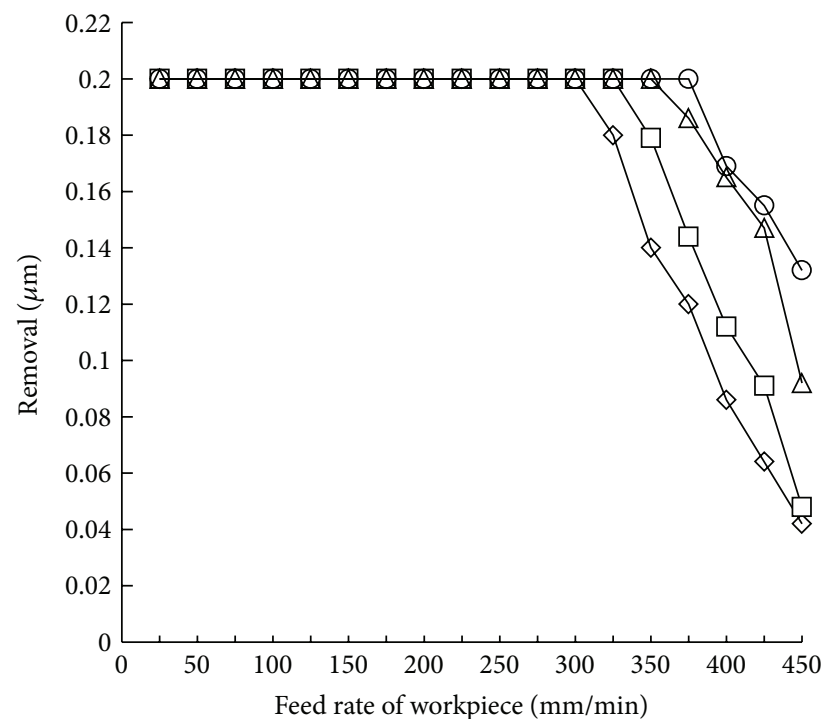

$\diamond 1000$ Gauss, $1000 \mathrm{~mm} \triangle 3000$ Gauss, $1400 \mathrm{~mm}$ $\neg-2000$ Gauss, $1200 \mathrm{~mm} \quad \bigcirc-4000$ Gauss, $1600 \mathrm{~mm}$

(a) Amount of $\mathrm{Si}_{3} \mathrm{~N}_{4}$ layer removed

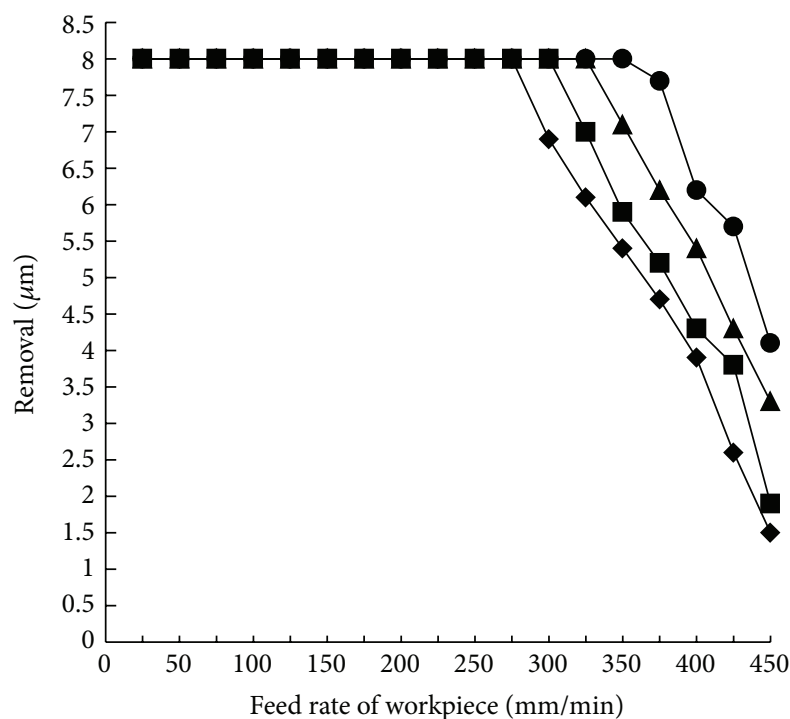

$\longrightarrow 1000$ Gauss, $1000 \mathrm{~mm} \longrightarrow 3000$ Gauss, $1400 \mathrm{~mm}$
$\rightarrow 2000$ Gauss, $1200 \mathrm{~mm}$ - 4000 Gauss, $1600 \mathrm{~mm}$

(b) Amount of epoxy film removed

FIGURE 5: Amount of $\mathrm{Si}_{3} \mathrm{~N}_{4}$ layer and epoxy film removed using different combinations of magnetic field strength and distance between the two magnets (phosphoric acid 25\% wt, $\mathrm{NaNO}_{3} 15 \% \mathrm{wt}$, PO4-3-P 5\% wt, $60^{\circ} \mathrm{C}, 40 \mathrm{~L} / \mathrm{min}$, continuous DC, $150 \mathrm{~A}, 80 \mathrm{~V}, 100 \mathrm{kHZ} / 150 \mathrm{~W}, \mathrm{shift}$ $800 \mathrm{rpm}$, and tool $900 \mathrm{rpm}$ ).

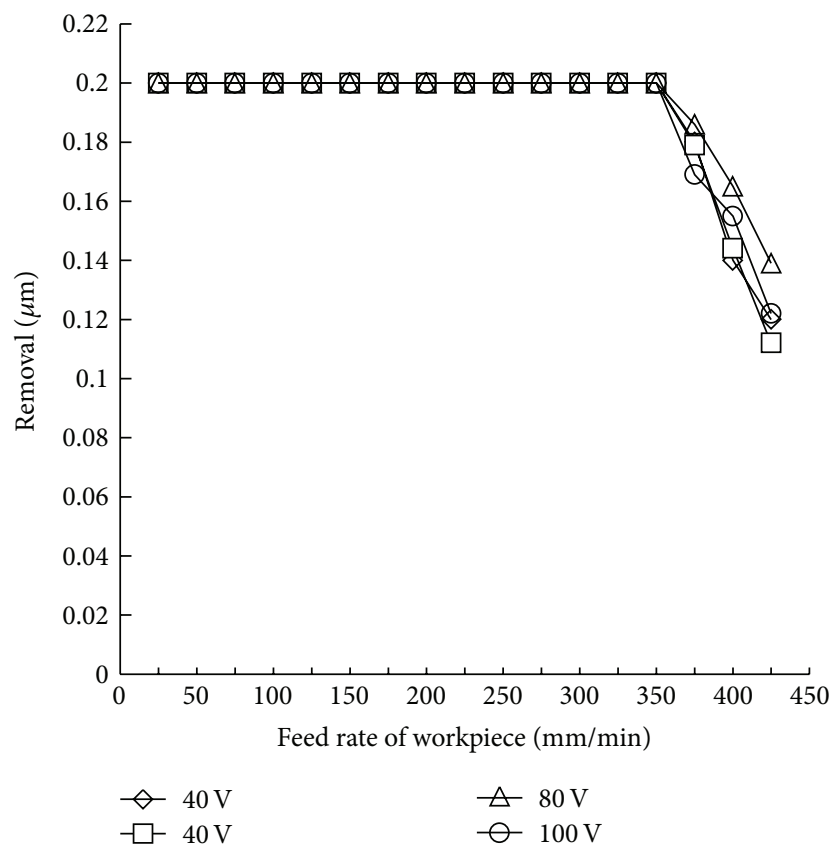

(a) Amount of $\mathrm{Si}_{3} \mathrm{~N}_{4}$ layer removed

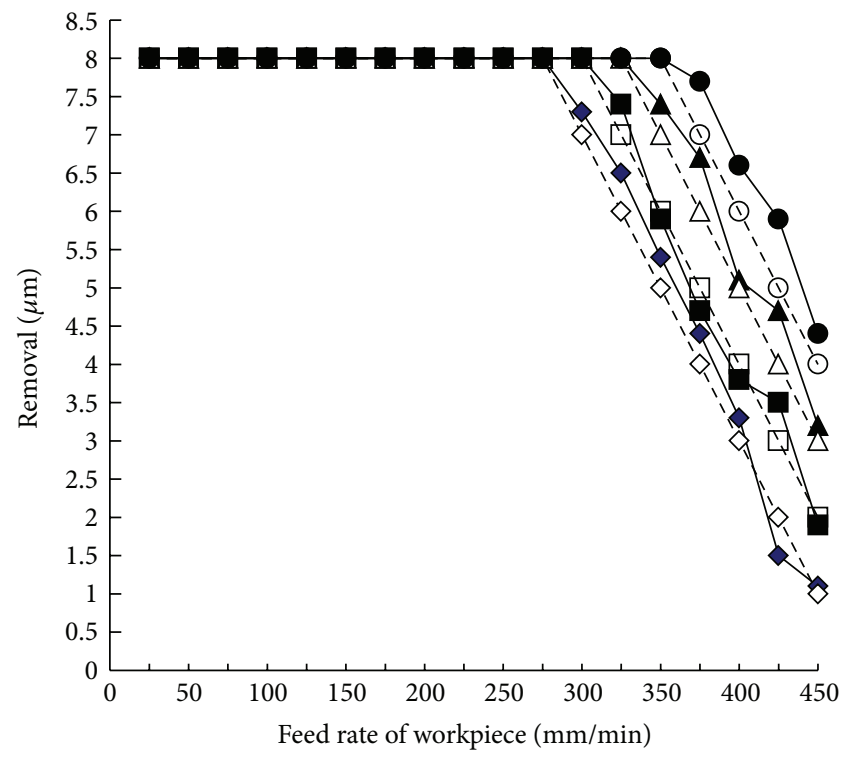

$\diamond-40 \mathrm{~V}$ (experimental results) $-\leftarrow 80 \mathrm{~V}$ (experimental results)
$-\diamond-40 \mathrm{~V}$ (theoretical prediction) $-\Delta-80 \mathrm{~V}$ (theoretical prediction)
$--60 \mathrm{~V}$ (experimental results) $-\bullet-100 \mathrm{~V}$ (experimental results)
$-\boxminus-60 \mathrm{~V}$ (theoretical prediction) $-\Theta-100 \mathrm{~V}$ (theoretical prediction)

(b) Amount of epoxy film removed

Figure 6: Amount of $\mathrm{Si}_{3} \mathrm{~N}_{4}$ layer and epoxy film removed at different workpiece feed rates using different currents (phosphoric acid 25\% wt, $\mathrm{NaNO}_{3} 15 \%$ wt, PO4-3-P 5\% wt, $60^{\circ} \mathrm{C}, 40 \mathrm{~L} / \mathrm{min}$, continuous DC, $150 \mathrm{~A}, 100 \mathrm{kHZ} / 150 \mathrm{~W}, 4000$ Gauss, shift $800 \mathrm{rpm}$, and tool $900 \mathrm{rpm}$ ). 




(a) Amount of $\mathrm{Si}_{3} \mathrm{~N}_{4}$ layer removed

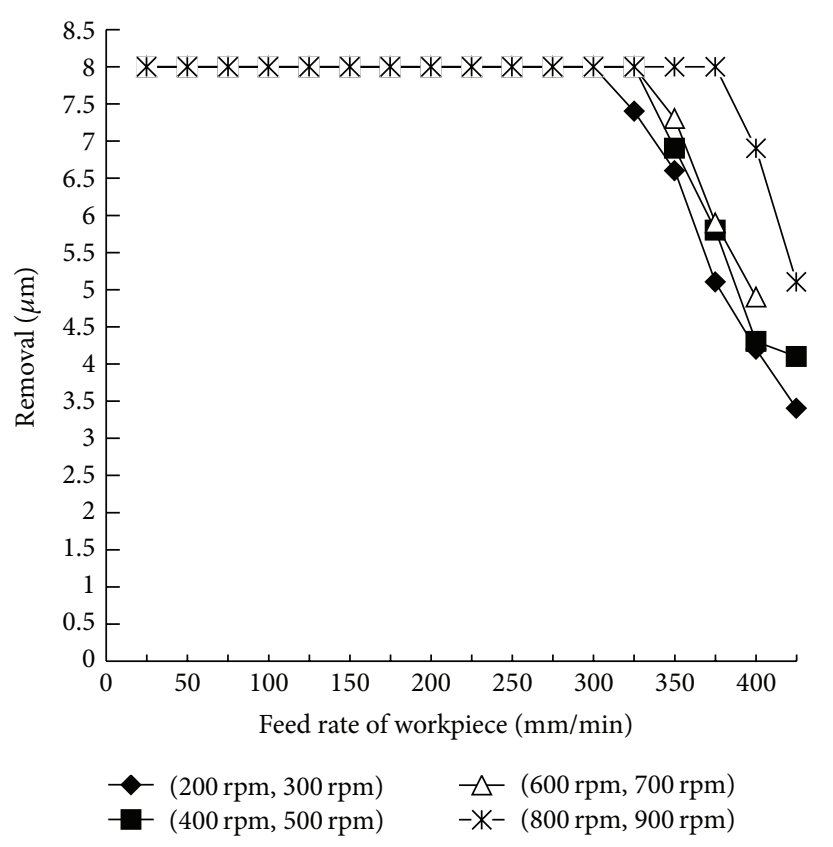

(b) Amount of epoxy film removed

FIGURE 7: Amount of $\mathrm{Si}_{3} \mathrm{~N}_{4}$ layer and epoxy film removed at different feed rates of workpiece using different combinations of tool revolution speed (shift) and tool rotational speed (phosphoric acid $25 \% \mathrm{wt}, \mathrm{NaNO}_{3} 15 \% \mathrm{wt}, \mathrm{PO} 4-3-\mathrm{P} 5 \% \mathrm{wt}, 60^{\circ} \mathrm{C}, 40 \mathrm{~L} / \mathrm{min}$, continuous $\mathrm{DC}, 150 \mathrm{~A}$, $100 \mathrm{kHZ} / 150 \mathrm{~W}$, and 4000 Gauss).

Squaring and simplifying (5),

$$
h=\frac{\left[L_{c}+2(g+y)\right] \omega^{2}}{4\left(\omega_{v}^{2}-\omega^{2}\right)},
$$

where $\omega_{v}$ is the feed rate of the workpiece and $\omega$ is the removal rate in the longitudinal direction. From (6),

$$
\begin{aligned}
h= & \frac{L_{c}+2(g+y)}{(g+y)^{2}} \\
& \left.\times\left[\frac{E \sigma}{F \rho\left(\left(n_{A} / M_{A}\right) a_{A}+\left(n_{B} / M_{B}\right) a_{B}+\cdots\right)}\right]^{2}\right) \\
& \times\left(4 \omega_{v}{ }^{2}-\frac{4}{(g+y)^{2}}\right. \\
& \left.\quad \times\left[\frac{E \sigma}{F \rho\left(\left(n_{A} / M_{A}\right) a_{A}+\left(n_{B} / M_{B}\right) a_{B}+\cdots\right)}\right]^{2}\right)^{-1} .
\end{aligned}
$$

From (7) it can be seen that the experimental results agree with the theoretical prediction (see Figure 6(b)). The experimental results show that the removal amount is directly proportional to the DC electric voltage $(E)$ and is inversely proportional to the feed rate of the workpiece $\left(\omega_{v}\right)$, which agrees with the theoretical prediction (see Figure 6(b)).

Figure 7 shows that the combination of high speed revolution (shift) with high speed rotation of the tool increases the discharge mobility and improves the removal effect required for a high feed rate of the workpiece. The high revolution (shift) speed and the higher rotational speed provide more kinetic energy to the electrolyte for dregs discharge and produce a better electrochemical micromachining and removal effect. In this system the ultrasonic vibration, electromagnetic forces, the higher revolution (shift), and rotational speeds combine to produce an efficient and complete discharge of the dregs.

Figure 8 shows the effects of the combination of the anode radius $\left(r_{a}\right)$ and cathode radius $\left(r_{c}\right)$ on the removal process. Decreasing these radii results in more open space which in turn reduces the resistance to dregs discharge and results in a more effective flushing path along the features of the tool and the silicon wafer surface and consequently also reduces the time required for removal of a given amount of epoxy and $\mathrm{Si}_{3} \mathrm{~N}_{4}$ thin film.

Figure 9 shows the effects of different diameters $\left(D_{c}\right)$ of cathode on the removal process. Figure 9(a) shows that a small diameter $\left(D_{c}\right)$ cathode and a large gap between the cathode and the silicon wafer surface reduce the time taken for the removal process. Once again it can be demonstrated that the electrochemical reaction products (dregs) are more easily discharged from a large machining gap. The results in Figure $9(\mathrm{~b})$ illustrate that a large diameter $\left(D_{c}\right)$ cathode and a small gap between the cathode and the silicon wafer surface reduce the time required for removal of a given amount of epoxy nanostructure since the microelectroetching effect is more easily developed with an adequate supply of electrochemical power. The experimental results show that small 


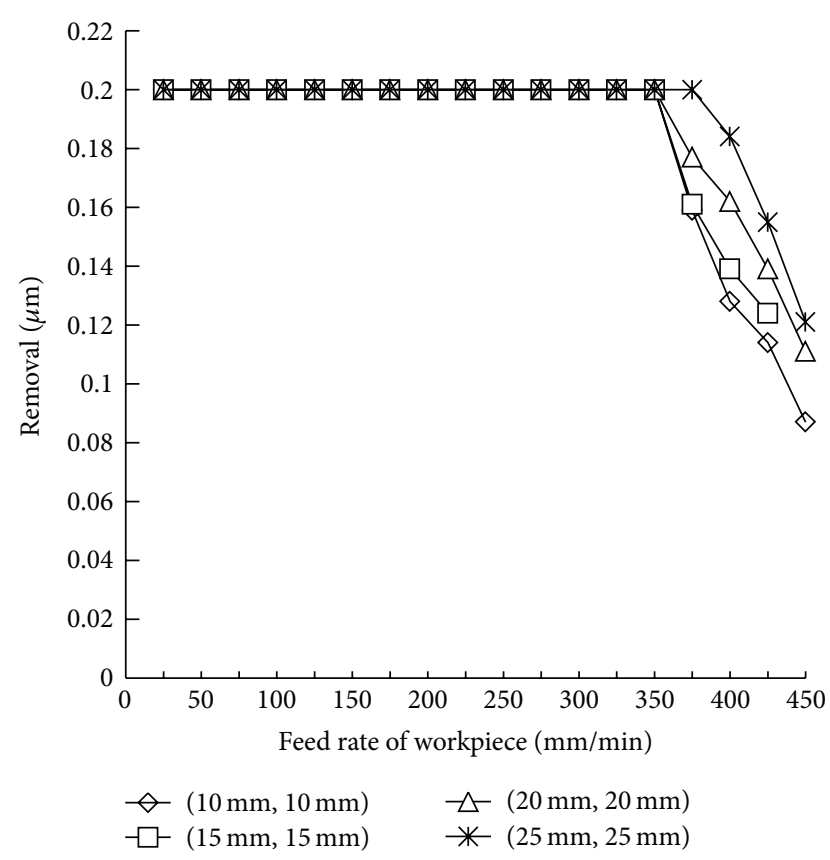

(a) Amount of $\mathrm{Si}_{3} \mathrm{~N}_{4}$ layer removed

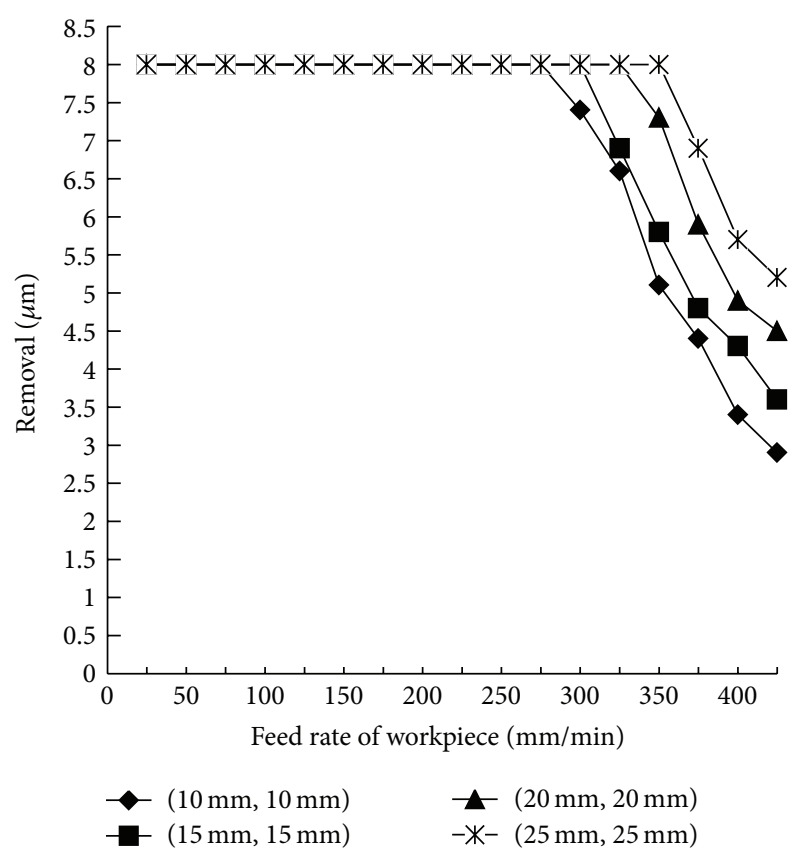

(b) Amount of epoxy film removed

FIGURE 8: Amount of $\mathrm{Si}_{3} \mathrm{~N}_{4}$ layer and epoxy film removed at different workpiece feed rates using different combinations of anode radius $\left(r_{a}\right)$ and cathode radius $\left(r_{c}\right)$ (phosphoric acid 25\% wt, $\mathrm{NaNO}_{3} 15 \% \mathrm{wt}, \mathrm{PO} 4-3-\mathrm{P} 5 \% \mathrm{wt}, 60^{\circ} \mathrm{C}, 40 \mathrm{~L} / \mathrm{min}$, continuous DC, $150 \mathrm{~A}, 100 \mathrm{kHZ} / 150 \mathrm{~W}$, 4000 Gauss, shift $800 \mathrm{rpm}$, and tool $900 \mathrm{rpm})$.

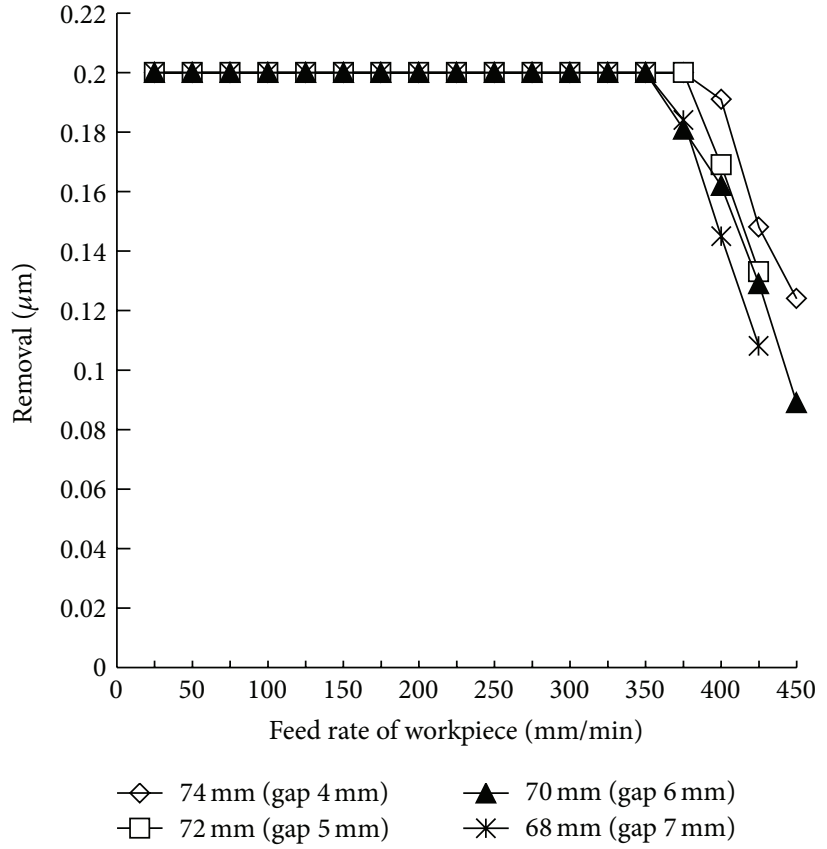

(a) Amount of $\mathrm{Si}_{3} \mathrm{~N}_{4}$ layer removed

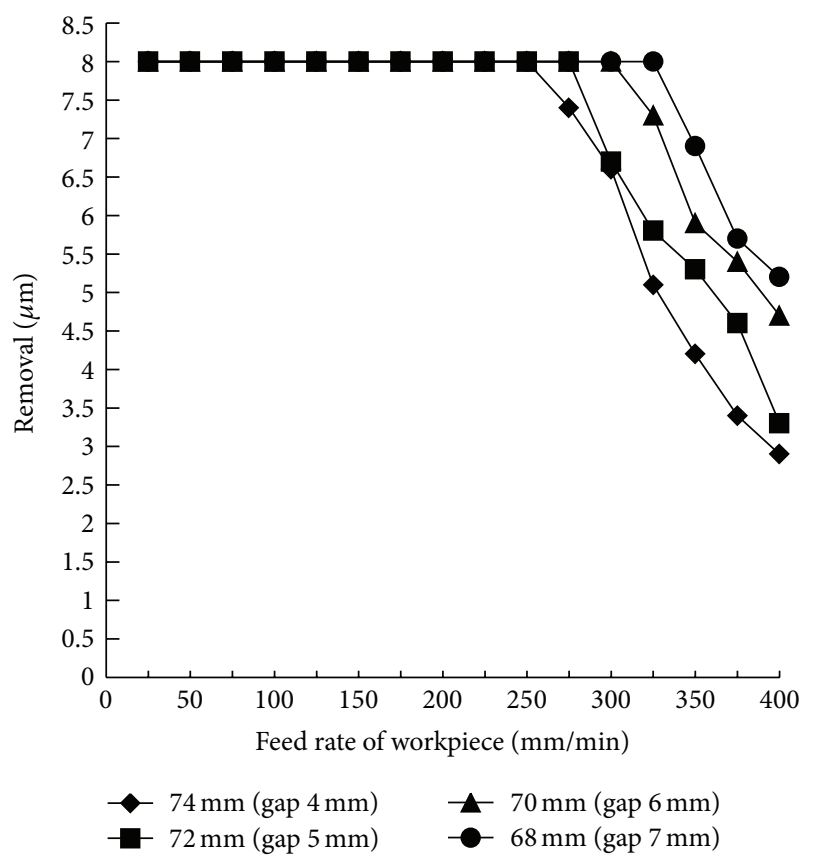

(b) Amount of epoxy film removed

FIGURE 9: Amount of $\mathrm{Si}_{3} \mathrm{~N}_{4}$ layer and epoxy film removed at different feed rates of workpiece using different diameters $\left(D_{c}\right)$ of cathode and different sizes of gap between the anode and cathode (phosphoric acid 25\% wt, $\mathrm{NaNO}_{3} 15 \% \mathrm{wt}, \mathrm{PO} 4-3-\mathrm{P} 5 \% \mathrm{wt}, 60^{\circ} \mathrm{C}, 40 \mathrm{~L} / \mathrm{min}$, continuous DC, 150 A, $100 \mathrm{kHZ} / 150 \mathrm{~W}, 4000$ Gauss, shift $800 \mathrm{rpm}$, and tool $900 \mathrm{rpm}$ ). 
gaps $(4 \mathrm{~mm})$ combined with a high continuous DC voltage and a high workpiece feed rate reduce microelectroetching time. However, discharge of the dregs from a small gap is difficult. To ensure stable operation of a microelectroetching and ECM process, a gap of $5 \mathrm{~mm}$ was found to be optimal.

In the current study, (7) can also be used to explain how controlling the stable reciprocal resistance $(\sigma)$ can improve the finishing effect. Increased discharge mobility (shift revolution, tool rotation, ultrasonic vibration, magnetic force, etc.), guiding discharge transport, and the provision of a clear flushing path will establish reciprocal resistance $(\sigma)$ stability. High speed revolution (shift) and rotation of the newly designed tool; high frequency and high power ultrasonics and a high rate of electrolyte flow; high magnetic field strength from magnets that are close together; and small anode and cathode radii all lead to better removal of the epoxy film and $\mathrm{Si}_{3} \mathrm{~N}_{4}$ layers.

\section{Conclusions}

The newly designed tool and process achieve the precise recycling of solar-cell silicon wafers by removing the hybrid composites coatings of epoxy and silicon nitride $\mathrm{Si}_{3} \mathrm{~N}_{4}$ from the surface of the wafer cleanly and easily. This precise process facilitates the recycling of defective or used wafers in the solar optoelectronic industry making it possible to return defective and used wafers to production. A large cathode rotation diameter provides a small gap between the anode and cathode to give a high rate of layer removal. High frequency and high power ultrasonics and a large electrolyte flow rate, high magnetic field strength from magnets that are close together, or small anode and cathode radii all increase dregs discharge and reduce the time taken to cleanly remove the composite layers of epoxy and $\mathrm{Si}_{3} \mathrm{~N}_{4}$. Dregs discharge is also improved by high speed revolution (shift) and rotation of the tool. This increased rate of discharge combined with a high continuous DC current flow results in a higher removal rate and consequently also allows a higher feed rate to be used. The study successfully demonstrates practical recycling of the defective wafers produced in the solar-cell silicon wafer process and their return to production. The proposed approach not only avoids the loss of silicon, since there is no abrasion, but also lowers costs and raises efficiency.

\section{Acknowledgments}

This study was supported by Ben Ten The Co. and by the National Science Council, Contracts 101-2221-E-152 -002 and 102-2221-E-152-005.

\section{References}

[1] E. Mathioulakis and V. Belessiotis, "A new heat-pipe type solar domestic hot water system," Solar Energy, vol. 72, no. 1, pp. 1320, 2002.

[2] H. J. Moller, Semiconductors for Solar Cells, vol. 35, Artech House, Norwood, UK, 1993.

[3] M. F. Turner, "How does your company measure up," Black Enterprise, vol. 32, no. 4, pp. 52-53, 2001.
[4] A. W. Czanderna and F. J. Pern, "Encapsulation of PV modules using ethylene vinyl acetate copolymer as a pottant: a critical review," Solar Energy Materials and Solar Cells, vol. 43, no. 2, pp. 101-181, 1996.

[5] E. Radziemska and P. Ostrowski, "Recycling of silicon in the PV industry," Ecology and Technology, vol. 17, no. 2, pp. 47-52, 2009.

[6] R. Ewa, O. Piotr, C. Adam, and S. Mirosław, "Chemical, thermal and laser processes in recycling of photovoltaic silicon solar cells and modules," Ecological Chemistry and Engineering S, vol. 17, no. 3, pp. 385-391, 2010.

[7] M. Badelt, C. Beerwald, A. Brosius, and M. Kleiner, "Process analysis of electromagnetic sheet metal forming by onlinemeasurement and finite element simulation," in Proceedings of the 6th International Conference on Materials Forming (ESAFORM '03), pp. 123-126, Salermo, Italy, 2003.

[8] D. Wei, X. Lu, Z. Lu, and J. Gu, "Performance analysis and optimization of Organic Rankine Cycle (ORC) for waste heat recovery," Energy Conversion and Management, vol. 48, no. 4, pp. 1113-1119, 2007.

[9] Y. H. Zou and T. Shinmura, "Mechanism of a magnetic field assisted finishing process using a magnet tool and magnetic particles," Key Engineering Materials, vol. 339, pp. 106-113, 2007.

[10] J. Unger, M. Stiemer, B. Svendsen, and H. Blum, "Multifield modeling of electromagnetic metal forming processes," Journal of Materials Processing Technology, vol. 177, no. 1-3, pp. 270-273, 2006.

[11] R. W. Wood and A. L. Loomis, "The physical and biological effects of high-frequency sound-waves of great intensity," Philosophical Magazine, vol. 4, no. 22, pp. 417-436, 1927.

[12] L. D. Rozenberg, V. F. Kazemtsev, L. O. Makrov, and D. F. Yakhimovich, Ultrasonic Cutting, Consultants Bureau, New York, NY, USA, 1964.

[13] B. L. Anantha Ramu, R. Krishnamurthy, and C. V. Gokularathnam, "Machining performance of toughened zirconia ceramic and cold compact alumina ceramic in ultrasonic drilling," Journal of Mechanical Working Technology, vol. 20, pp. 365-375, 1989.

[14] R. Gilmore, "Ultrasonic machining: a case study, Journal of Materials Processing Tech, vol. 28, no. 1-2, pp. 139-148, 1991.

[15] B. H. Amstead, F. Philip, F. Ostwald, and L. Myron, Manufacturing Processes, John Wiley \& Sons, New York, NY, USA, 1977.

[16] J. A. McGeough, Principles of Electrochemical Machining, Chapman and Hall, London, UK, 1974.

[17] V. K. Jain and V. N. Nanda, "Analysis of taper produced in side zone during ecd," Precision Engineering, vol. 8, no. 1, pp. 27-33, 1986.

[18] M. Datta and D. Landolt, "Electrochemical machining under pulsed current conditions," Electrochimica Acta, vol. 26, no. 7, pp. 899-907, 1981.

[19] B. H. Kim, S. H. Ryu, D. K. Choi, and C. N. Chu, "Micro electrochemical milling," Journal of Micromechanics and Microengineering, vol. 15, no. 1, pp. 124-129, 2005.

[20] H. Hocheng and P. S. Pa, "Continuous secondary ultrasonic electropolishing of an SKD61 cylindrical part," International Journal of Advanced Manufacturing Technology, vol. 21, no. 4, pp. 238-242, 2003.

[21] P. S. Pa, "Design of effective plate-shape electrode in ultrasonic electrochemical finishing," International Journal of Advanced Manufacturing Technology, vol. 34, no. 1-2, pp. 70-78, 2007.

[22] P. S. Pa, "Design of thread surface finish using ultrasonic-aid in electrochemical leveling," International Journal of Advanced Manufacturing Technology, vol. 36, no. 11-12, pp. 1113-1123, 2008. 
[23] P. S. Pa, "Synchronous finishing processes using a combination of grinding and electrochemical smoothing on end-turning surfaces," International Journal of Advanced Manufacturing Technology, vol. 40, no. 3-4, pp. 277-285, 2009.

[24] P. S. Pa, "Continuous finishing processes using a combination of burnishing and electrochemical finishing on bore surfaces," International Journal of Advanced Manufacturing Technology, vol. 49, no. 1-4, pp. 147-154, 2010.

[25] H. Xiao, Introduction to Semiconductor Manufacturing Technology, Prentice Hall, New York, NY, USA, 2001.

[26] Z. J. Pei and A. Strasbaugh, "Fine grinding of silicon wafers: designed experiments," International Journal of Machine Tools and Manufacture, vol. 42, no. 3, pp. 395-404, 2002.

[27] M. H. Nagel, "Environmental supply-chain management versus green procurement in the scope of a business and leadership perspective," in Proceedings of the IEEE International Symposium on Electronics and the Environment (ISEE '00), pp. 219-224, San Francisco, Calif, USA, October 2000. 

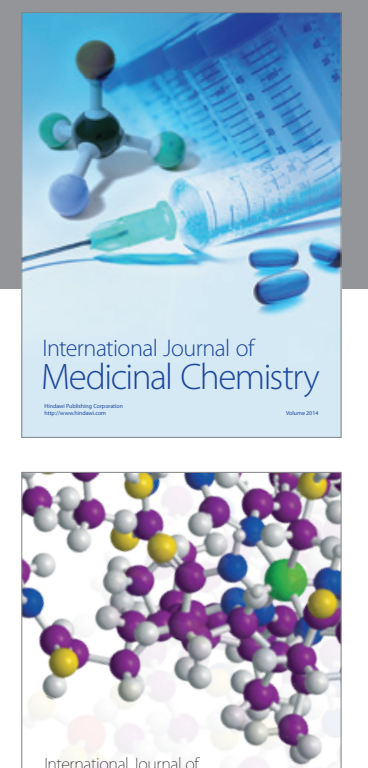

\section{Carbohydrate} Chemistry

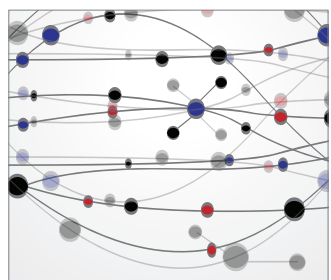

The Scientific World Journal
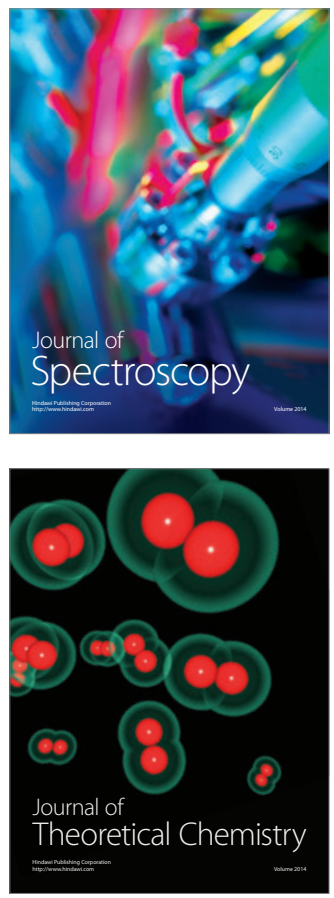
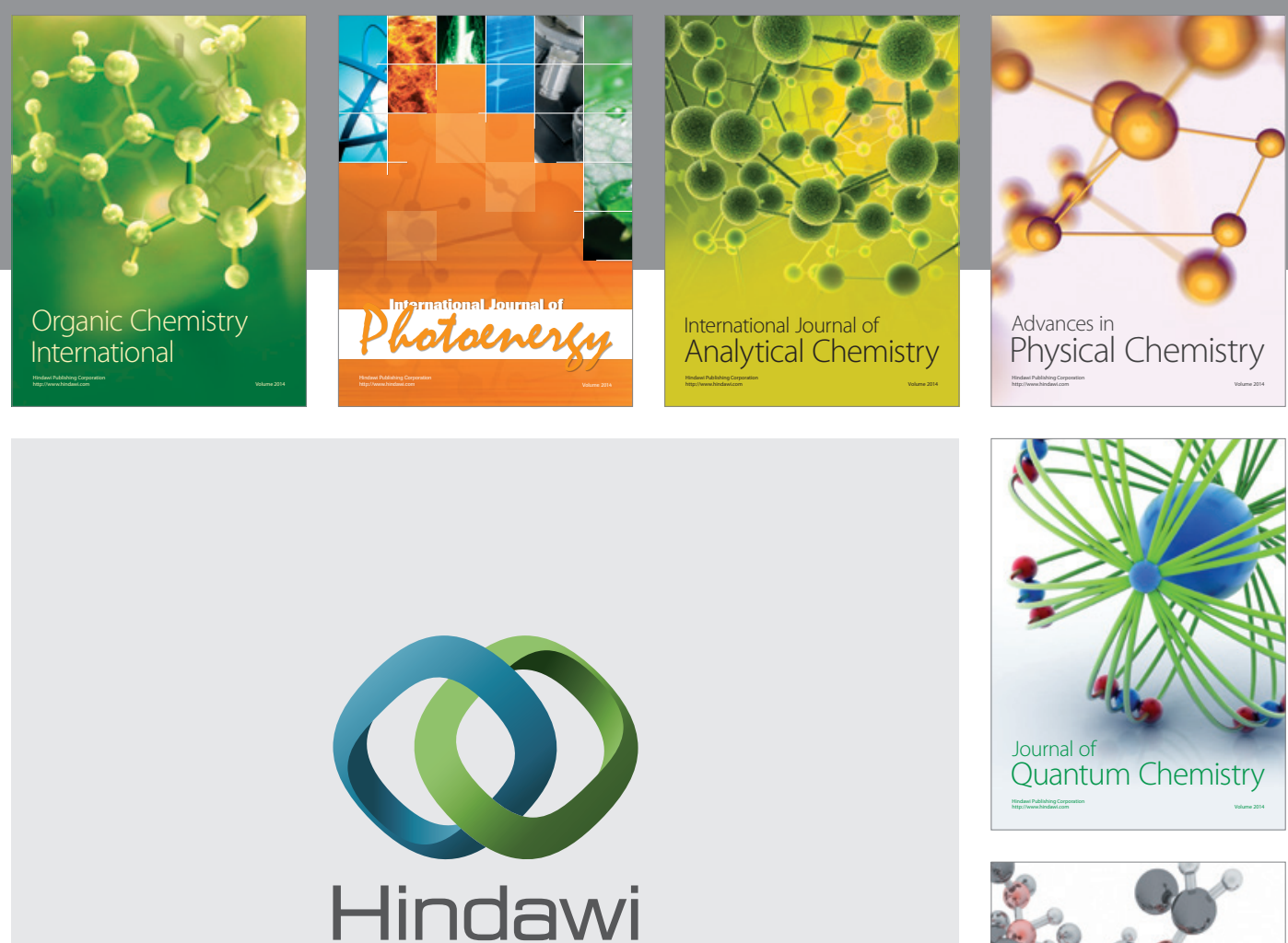

Submit your manuscripts at

http://www.hindawi.com

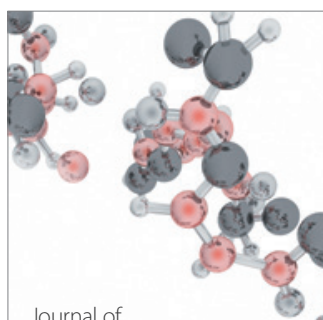

Analytical Methods

in Chemistry

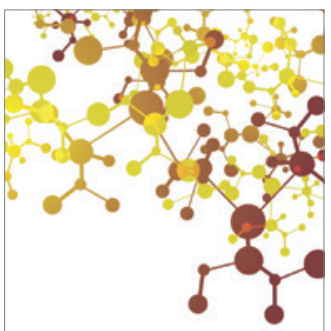

Journal of

Applied Chemistry

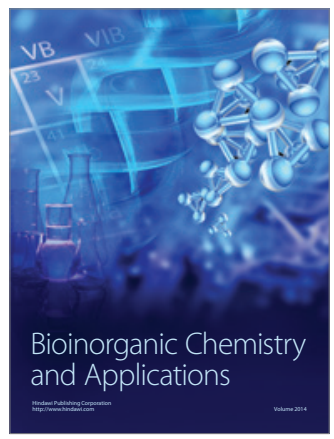

Inorganic Chemistry
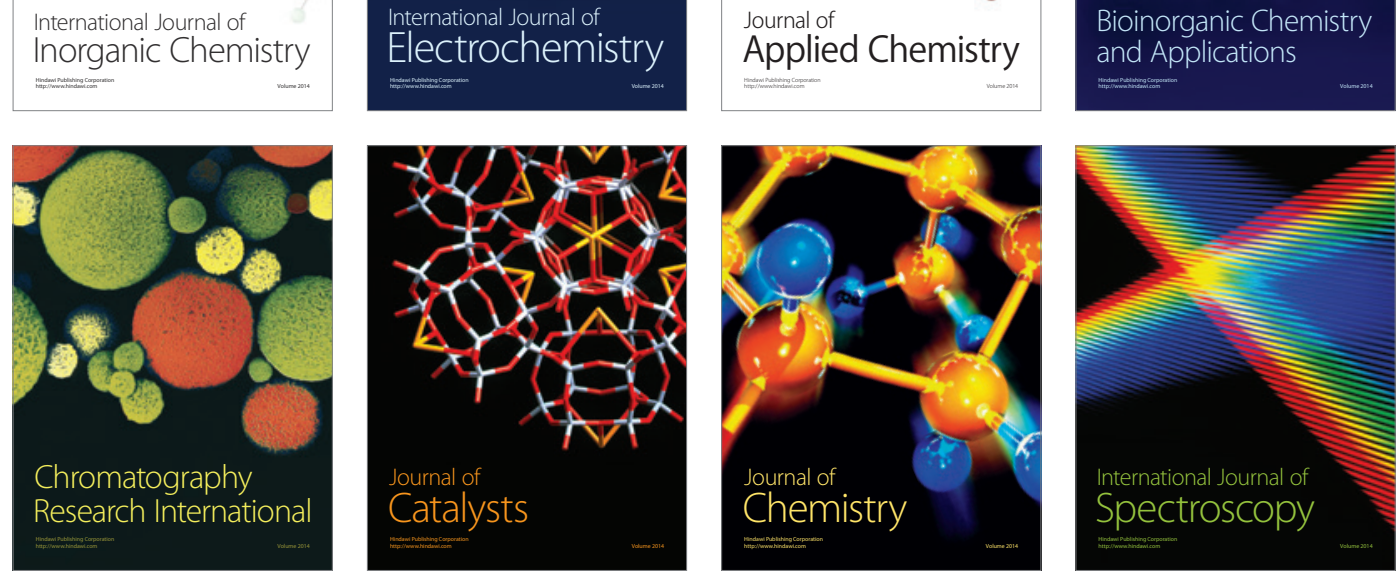